Preference is given to letters commenting on contributions published recently in the JRSM. They should not exceed 300 words and should be typed double spaced

\section{Is learning driven by teaching or research?}

Professor Leinster (January $2004 J R S M^{1}$ ) states that there has yet been no proof that high-quality teaching in universities is correlated to high-quality research:- a point often expressed by the senior politicians and civil servants responsible for higher education. However, during the last decade it was often remarked that, to cursory examination, there was a remarkable coincidence between those university departments that scored highly in the research assessment exercises (RAEs) and those that scored highly in the teaching quality assessments. All of this information is in the public domain: has nobody yet analysed it?

More to the point is the suggestion, in his excellent article, that to look for a correlation between research and teaching is to obscure the irrefragable relationship between research and learning. Learning, and acquiring the skill of how to learn, can only take place in an environment of discovery provided through research.

However, I must challenge some of Professor Leinster's facts in his analysis of the RAE and its outcomes. The RAE was actually a 7 (not 5) point scale. A curiously English invention, it ran from 1 to 5 , but with grades $3 a$ and $3 b$ and 5 and $5 *$ there are actually 7 points. More importantly, it is not true that only the highest (5 and $5 *$ ) grades were funded. $4 \mathrm{~s}$ were funded, but at a lower level than previously. 3s were funded for the first year; $3 a$ s in unit of assessment 11 (professions allied to medicine) continue to receive 'developmental' funding.

But it is the philosophical basis of his contention that is a double-edged sword. Yes, it may well be deplorable to remove research funding from departments engaged in medical education, because the subsequent demise of research activity will inevitably damage the inquisitive learning that is necessary if we are to maintain the highest quality supply of educated doctors capable of advancing their profession. However, if the research of some departments has been judged not to be of the highest grade (i.e. 5/5*), does this not, by his own argument, suggest that the learning will also be second rate? Or is 'good enough' research sufficient to produce 'good enough' doctors?

I will be the first to admit that there is no comfortable answer to these issues. I do believe that research which has been judged to be of (at least) 'national levels of achievable excellence' is not only worth encouraging, but is also a valuable and positive beneficial stimulus to students' learning, and therefore should be supported. The essential problem is that, in the UK, we are world beaters at producing excellence in both research and teaching for the minimum financial input, and that the indisputable increases in both the quality and quantity of our teaching and research over the past years has outstripped the nation's political desire to provide adequate funding. This not only affects medical education but also has a major negative impact on strategic research undertaken by our universities that might otherwise support innovation and growth in the domestic economy.

\section{Michael Trevan}

University of Westminster, Cavendish Campus, 115 New Cavendish Street, London W1M 8JS, UK

E-mail: mtrevan@lineone.net

\section{REFERENCE}

1 Leinster S. Medical schools: are we paying for education or for technical training? J R Soc Med 2004;97:3-5

\section{John Snow and anaesthesia}

As an admirer of all that Dr Stanwell-Smith has done for the John Snow Society, I comment reluctantly on her review (December $2003 J R S M^{1}$ ) of the recently published biography. ${ }^{2}$ Why does she describe Snow as curmudgeonly? Sir Charles Locock, in his 1859 presidential address to the Royal Medical and Chirurgical Society, eulogized Snow as follows: 'Dr. Snow was recognized everywhere as a remarkably modest and unassuming man, strictly honorable, of a thoroughly amiable disposition, and few have been more regretted by all who had the pleasure of knowing him.' Hardly the description of a curmudgeon.

How did his decision to specialize in 'the new and controversial technique of anaesthesia' militate against the recognition of his contribution to medicine? The controversy, if it had any existence at all, was against obstetric analgesia, and did not last long. Snow could list the Queen and members of the nobility among his patients. His contribution to the science of anaesthesia was well recognized in his lifetime, and has been ever since. He is one of the supporters of the Royal College of Anaesthetists' coat of arms, and the Association presents a John Snow Silver Medical.

There would be no point in the Michigan-based authors belonging to the John Snow Society, because it does not publish proceedings. However, I, who was the authors' gofer on this side of the Atlantic for some four years, and whose name appears on the title page, have been a member for more than ten, and I can testify that three of the authors, during visits to London, bought memorabilia from the John Snow Society and visited the eponymous pub.

I was present at the late Dick Ellis's memorable Blessed Chloroform Lecture. That there has been only one does not indicate a lack of interest in Snow; the Proceedings of the
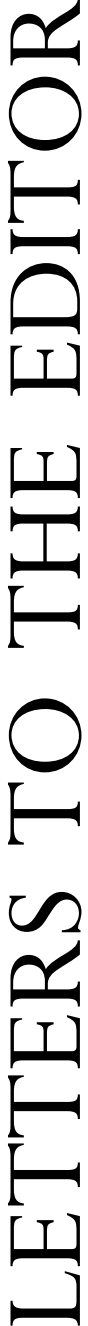
History of Anaesthesia Society and the anaesthetics journals provide evidence to the contrary. Has anyone been invited to deliver a second Blessed Chloroform Lecture? Anaesthetists being a self-effacing lotit goes with the specialtyare not going to nominate themselves.

\section{David Zuck}

Craigower, St Andrew's Close, London N12 8BA, UK

\section{REFERENCES}

1 Stanwell-Smith R. Book of the month. J R Soc Med 2003;96:612-13

2 Vinten-Johansen P, Brody H, Paneth N, Rachman S, Rip M. Cholera, Chloroform, and the Science of Medicine: a Life of John Snow. Oxford: Oxford University Press, 2003

\section{John Snow and St George's}

In her review of Cholera, Chloroform and the Science of Medicine: A Life of John Snow (December $2003 J_{R S M}^{1}$ ) Rosalind Stanwell-Smith is right to point out that John Snow's achievements have met with little recognition in Britain, while his true worth has been properly celebrated in the USA, because of 'the traditional British manner of delayed acknowledgement of non-military heroes (particularly in science)'. In 1847, John Snow was invited to give ether anaesthetics to dental outpatients at St George's Hospital and in A Short History of St George's Hospital (Athlone 1997) Terry Gould, an anaesthetist himself, wrote 'St George's may proudly boast of its connection with this great medical pioneer'. However, in 1997, when Dr Alex Thurlow and some of his anaesthetic colleagues at $\mathrm{St}$ George's Hospital made a formal proposal to call his department 'The John Snow Department of Anaesthesia' it was rejected by the majority of anaesthetists there. They obviously thought that a ward and a pub named after John Snow were sufficient honour.

\section{Graham Barker}

Portland Hospital, London W1W 5AH, UK

\section{REFERENCE}

1 Stanwell-Smith R. Cholera, Chloroform and the Science of Medicine: A Life of John Snow [Book of the Month]. J R Soc Med 2003;96:612-13

\section{Evidence-based and complementary medicine}

The two articles on evidence-based medicine versus complementary medicine, published in the January 2004 $J R S M^{1,2}$, would perhaps be more convincing if they did not ignore the numerous drugs which we are happy to peddle and the benefits of which, while 'evidence-based', are all too obviously either doubtful or negative. As I survive into retirement I have to listen more and more to the tablets. Many are on six or more different compounds, often given to counteract the side-effects of the others. Some are more or less disabled by their pills. As a purely social acquaintance one cannot be too inquisitive about the exact identities of the substances involved, but ordinary conversation often raises doubts about what has been prescribed and what for.

An example might be provided by a close relation, aged 74, who was found at a routine examination to have a marginally raised blood pressure. He was given medication for this, and as a consequence suffered from dizziness, which prevented him from driving a car. He went back to the surgery, where he saw another doctor, who put him on another medicine for the dizziness. This gave him a dry mouth and indigestion, so he went back to the surgery again, where yet another doctor diagnosed depression and put him on an SSRI. Following this he became confused and inarticulate and even more depressed. His wife and daughters began to think about funeral arrangements. Fortunately he went back to the surgery again, where he saw the practice principal, a woman on the verge of retirement and still applying a measure of commonsense, who decided that there never had been any hypertension and took him off all medication. He is now symptom-free and alert and drives his car all over the county where he lives.

This is an anecdote. Does that mean we must ignore it? How many such anecdotes constitute evidence? How can there be a controlled trial of old folk who are on too many pills? Which drug company will subsidize such a trial?

My first experience as a house physician was in 1955 with Donald Hunter, then senior physician to the London Hospital. He used to say that we were leaving the period of dangerous surgery and entering that of dangerous medicine. He seems to have been right.

Stephen Butterworth

Park Farm Lodge, Park Road, Marden, Kent TN12 9LG, UK

\section{REFERENCES}

1 Koutouvidis N. CAM and EBM: arguments for convergence. J R Soc Med 2004;97:39-40

2 Ernst E. Patient choice and complementary medicine. $J$ S Soc Med 2004;97:41

\section{Diagnosis of abdominal tuberculosis}

From their retrospective survey (December $2003 \mathrm{JRSM}^{1}$ ) $\mathrm{Mr}$ Rai and $\mathrm{Mr}$ Thomas conclude that, in suspected abdominal tuberculosis, diagnostic laparoscopy is the investigation of choice. They do not refer to a similar report by myself and colleagues on 14 patients, in which we recommended diagnostic laparoscopy when the Mantoux 
test and/or ascitic fluid microscopy are negative. ${ }^{2}$ In Rai and Thomas' series it is difficult to know whether all 25 patients truly required this investigation. Do the authors advocate diagnostic laparoscopy as the primary investigation, or only when simpler and less costly tests have been uninformative?

\section{Singh-Ranger}

Academic Department of Surgery, Royal Free and UCH Medical Schools,

Charles Bell House, 67/73 Riding House Street, London W1W 7ED, UK

\section{REFERENCES}

1 Rai S, Thomas WM. Diagnosis of abdominal tuberculosis: the importance of laparoscopy. J R Soc Med 2003;96:586-8

2 Singh-Ranger D, Rockall T, Narward A-H, et al. Abdominal tuberculosis: the problem of diagnostic delay. Scand J Infect Dis 1999;31:517

We agree with the argument presented by Mr Rai and $\mathrm{Mr}$ Thomas (December $2003 J_{R S M}^{1}$ ) for earlier use of diagnostic laparoscopy in suspected abdominal tuberculosis (TB). However, even in the hands of experienced operators the risk is not negligible (though under 1\%). The complications, apart from those of general anaesthesia, include damage to blood vessels, bowel and bladder. In Rai and Thomas's series, seemingly, a polymerase chain reaction (PCR) test was not used on the 11 ascitic fluids when acid-fast bacilli were not found. A positive result might have avoided the need for laparoscopy; $;^{2,3}$ furthermore, PCR can help to distinguish Mycobacterium tuberculosis from $M$. avium in immunocompromised patients. ${ }^{3}$

In addition, although in 9 of 28 patients ultrasound showed evidence of TB, it seems that fine needle aspiration was not attempted in those with lymph node abnormalities, or colonoscopy in those with an ileocaecal mass. An ultrasound-guided biopsy ${ }^{4}$ or colonoscopy ${ }^{5}$ is indicated in the presence of lymphadenopathy, abscess or a focal lesion in the viscera. Finally, Rai and Thomas refer to low haemoglobin and raised C-reactive protein as a consistent feature but say nothing about $\mathrm{Ca}-125$, which can be high in abdominal tuberculosis. ${ }^{6}$

In our opinion, diagnostic laparoscopy should be used only when less invasive investigations yield no positive results.

\section{Michelle Petrou}

\section{Vassilis Vassiliou ${ }^{1}$}

University College London Medical School;

'Department of Medicine, Box 31, Addenbrooke's Hospital, Cambridge CB2 2QQ, UK E-mail:vassiliou@doctors.org.uk

\section{REFERENCES}

1 Rai S, Thomas WM. Diagnosis of abdominal tuberculosis: the importance of laparoscopy. $J$ R Soc Med 2003;96:586-8

2 Balian A, de Pinieux I, Bellonla D, et al. Abdominal tuberculosis: deceptive and still encountered. Presse Méd 2000;29:994-6

3 Bouma BJ, Tytgat KMAJ, Schipper HG, Kager PA. Be aware of abdominal tuberculosis. Neth J Med 1997;51:119-22
4 Malik A, Saxena NC. Ultrasound in abdominal tuberculosis. Abdom Imaging 2003;28:574-9

5 Ibrarullah M, Mohan A, Sarkari A, Srinivas M, Mishra A, Sundar TS Abdominal tuberculosis: diagnosis by laparoscopy and colonoscopy. Trop Gastroenterol 2003;23:150-3

6 Thakur V, Mukherjee U, Kumar K. Elevated serum cancer antigen 125 levels in advanced abdominal tuberculosis. Med Oncol 2001;18:89-91

\section{Authors' reply}

We agree that simple diagnostic tests should be tried first, though commonly unhelpful. All 25 patients in our series who underwent diagnostic laparoscopy had shown inconclusive Mantoux and ascitic fluid staining results. We have no experience with use of the PCR test on ascitic fluid in patients suspected of abdominal tuberculosis.

\section{S Rai}

\section{W M Thomas}

Department of General Surgery, Leicester General Hospital,

Leicester LE5 4PW, UK

Mr Rai and Mr Thomas (December 2003 JRSM ${ }^{1}$ ) outline the difficulties in diagnosing abdominal tuberculosis and suggest that early laparoscopy may aid diagnosis and reduce time for it to be made. In their case series of 36 patients the mean duration of presenting complaint was 18 months. The diagnosis of abdominal TB should be in clinicians' minds even in the acute setting. Recently an Asian woman aged 18 was referred to the gynaecologists with right iliac fossa pain. She spoke little English and history-taking was difficult. She was anaemic and the white cell count and C-reactive protein were raised. The surgeons were then consulted, and diagnosed acute appendicitis. Under anaesthesia a mass could be felt arising from the pelvis on the right, and a low midline incision was made. The entire peritoneal cavity was caked with tuberculous nodules with a normal-looking appendix and ovaries. Unfortunately, the patient died in intensive care a few days later. On further questioning of relatives it was found that the patient had arrived in the UK only a fortnight previously, after her marriage to a UK citizen, and had been experiencing abdominal pain and other symptoms for the past three months. In this patient the diagnosis could have been made at laparoscopy, avoiding the laparotomy. More importantly the case highlights the need for thorough history-taking and inclusion of abdominal TB in the differential diagnosis.

\section{P A Whitehouse}

Mayday University Hospital, Croydon, Surrey, UK

E-mail: pwhitehouse@doctors.org.uk

\section{REFERENCE}

1 Rai S, Thomas WM. Diagnosis of abdominal tuberculosis: the importance of laparoscopy. J R Soc Med 2003;96:586-8 


\section{Early trialists}

You are right (December $2003 J R S M^{1}$ ) to celebrate and recognize the James Lind Initiative, and one of the earliest accounts of a prospective controlled (clinical) trial recorded in A Treatise of the Scurvy (1753). Let us not, however, forget the initiative of de Lugo, born in Madrid in 1583. Having been cured of malaria by 'bark' from Peru around 1644, he instructed Gabriel Fonseca (the Pope's physician) to undertake a controlled trial before the Church could recommend its use.

\section{Harvey White}

149 Harley Street, London W1G 6DE, UK

\section{REFERENCES}

1 Chalmers I. The James Lind Initiative. J R Soc Med 2003;96:575-6

2 Honigsbaum M. The Fever Trail. London: Macmillan, 2001

\section{Intracranial aneurysm surgery and its future}

Mr Maurice-Williams and Mr Lafuente (November 2003 $J R S M^{1}$ ) must be congratulated for their erudite account of issues arising during the senior author's long and august career in neurovascular surgery. However, in the wake of the International Subarachnoid Aneurysm Trial (ISAT ${ }^{2}$ ) we believe their views regarding the future mode of treatment of intracranial aneurysms to be somewhat ill-founded.

The dilemma being considered is whether endovascular 'coiling' or neurosurgical 'clipping' of ruptured cerebral aneurysms is better for excluding the aneurysm sac from circulation. ISAT focuses on a specific subgroup of ruptured aneurysms believed by clinicians to be suitable for either mode of treatment but where there is uncertainty/ equipoise as to which line of treatment should be performed. Out of a total 9559 patients presenting with aneurysmal subarachnoid haemorrhage who were considered for the trial, only 2143 (22.5\%) fell into this subgroup and were randomized. Of these, the results of $1594(17 \%$ of the original total) were analysed at one year. The major outcome criterion was the risk of dependence or death at one year post treatment. The results show that $30.6 \%$ of those treated operatively and $23.7 \%$ of those treated endovascularly had poor outcomes - a $6.9 \%$ absolute risk reduction. There was no difference in mortality. Of the excluded patients, 3615 underwent clipping, 2737 underwent coiling and 1064 had an unknown management. ISAT did not follow up these patients. Conclusions from the trial data are not universally accepted. Some commentators have argued that the reported results can be entirely explained by a difference in experience of the doctors treating each group. ${ }^{3}$ It is likely that many surgical procedures were performed by non-specialist surgeons or by trainees.
The risk of requiring a second procedure (surgical or radiological) on the same aneurysm was found to be over four times higher in the group treated by the endovascular technique. $17 \%(136 / 801)$ of those treated endovascularly and $4 \%(34 / 793)$ of those treated surgically underwent further intervention. Of those coiled, 7\% (55/801) required further intervention more than a month after initial treatment, compared with $0.8 \%(6 / 793)$ of those who underwent clipping. Whereas clipping is considered a definitive treatment for ruptured aneurysms these data suggest that endovascular management is associated with a higher rate of re-treatment and hence late complications. To this should be added the morbidity associated with the inevitable follow-up cerebral angiography in those treated with coiling. The natural history of a coiled aneurysm is still unknown and, since this cohort of patients is still under follow-up, further results are awaited.

Endovascular embolization has been validated by ISAT to be a front-line treatment for non-complex anteriorcirculation aneurysms providing its availability is equivalent to that of the traditional surgical techniques. Further analysis of long-term outcomes is awaited. The ISAT results cannot be extrapolated to the large majority of ruptured aneurysms that are routinely managed by either clipping or coiling in which there is no management uncertainty (and which would therefore be excluded from the trial). ISAT has not demonstrated that coiling is the best treatment for all or even a majority of ruptured cerebral aneurysms presenting to neurosurgeons in the UK.

\section{J Tait}

\section{J S Norris}

Department of Neurosurgery, Hurstwood Park Neurosciences Centre, Haywards Heath LH16 4EX, UK

E-mail: m.tait@medix-uk.com

\section{REFERENCES}

1 Maurice-Williams RS, Lafuente J. Intracranial aneurysm surgery and its future. J R Soc Med 2001;96:540-3

2 International Subarachnoid Aneurysm Trial (ISAT) Collaborative Group. International Subarachnoid Aneurysm Trial (ISAT) of neurosurgical clipping versus endovascular coiling in 2143 patients with ruptured intracranial aneurysms: a randomised trial. Lancet 2002;360:1267-74

3 Harbaugh RE, Heros RC, Hadley MN. Position Statement on the International Subarachnoid Aneurysm Trial (ISAT). [www.aans.org/library/ article. aspx?articleid=9703]

\section{Upper-extremity thrombosis}

Dr Abdelaal and colleagues record the case of a man whose recurrent axillary vein thromboses were due to neuropathic arthropathy (December 2003, JRSM $M^{1}$ ). Thrombosis of the upper extremity is referred to as Paget-Schroetter syndrome. ${ }^{2}$ In 1875, Sir James Paget postulated that the cause of acute pain and swelling of the arm was spontaneous 
thrombosis of the veins draining the upper extremity. ${ }^{3}$ In 1884 , von Schroetter was the first to relate the clinical syndrome to thrombosis of the axillary and subclavian veins. ${ }^{4}$ Paget-Schroetter syndrome is also referred to as 'effort' thrombosis, because it occurs after unusually strenuous use of the arm and the shoulder. ${ }^{5}$ An anomaly at the thoracic outlet, such as compression of the subclavian vein between the first rib and a hypertrophied scalene or subclavian tendon, or between those two tendons themselves, is frequently found in affected patients. ${ }^{5}$ The prevalence of symptomatic upper-extremity deep vein thrombosis (DVT) was evaluated retrospectively at a community teaching hospital. ${ }^{6}$ It was diagnosed in 65 of 44136 patients of all ages $(0.15 \%)$. No patients developed symptomatic pulmonary embolism. Central lines at the site of thrombosis had been inserted in 39 of 65 patients; cancer was diagnosed in 30 of 65 patients ( 23 of the patients with cancer had central lines); and 19 patients had no apparent cause for their DVT. All patients had swelling of the upper extremities. Erythema over the affected site was present in 4 (6\%); pain was present in $26(40 \%)$, and all had discomfort from swelling.

\section{Ali S M Jawad}

Department of Rheumatology, Royal London Hospital, London E1 4DG, UK E-mail: alismjawadı@otmail.com

\section{REFERENCES}

1 Abdelaal E, White P, Lewis KE, Redfern RM, Harrison NK. Recurrent axillary vein thrombosis as a manifestation of syringomyelia. $J R$ Soc Med 2003;96:595-7

2 Hughes ESR. Venous obstruction in the upper extremity (PagetSchroetter's syndrome). Collective Review 1949;88:89

3 Paget J. Clinical Lectures and Essays. London: Longman Green, 1875

4 von Schroetter L. Erkrankungen der gefasse. In: Nothnagel CWH, et al. Handbuch der Pathologie und Therapie. Wein: Holder, 1884

5 Molina JE. Surgery for effort thrombosis of the subclavian vein. J Thorac Cardiovasc Surg 1992;103:341-6

6 Mustafa S, Stein PD, Patel KC, Otten TR, Holmes R, Silbergleit A. Upper extremity deep venous thrombosis. Chest 2003;123:1953-6

\section{Reducing the toll of road traffic accidents}

No doubt I shall not be the only person to rise to John Bache's bait (December $2003 J R S M^{1}$ ). He gives an unsubstantiated opinion that elderly drivers are a serious cause of accidents because their reaction times, memories, concentration and visual acuity are poor. May I give an equally unsubstantiated alternative view? I suggest that elderly people might not cause more accidents, because they drive more slowly, take fewer risks, are less prone to 'road rage' or being provoked by it and have a life-time's driving experience behind them. Furthermore, the elderly have learned not to mix drink, drugs and driving and the drugs they take may be less hazardous than so-called recreational ones. Physical frailty is not a problem with modern cars, except for getting in and out of them (why are car doors not made hinged from the rear, as in London taxis?). I agree that requirements for driving licences need changing; for example, visual fields are as important as visual acuity, at all ages.

The only hard evidence I know of to support my view is that insurance premiums are not universally loaded against the old as they are against the young, and insurers are very knowledgeable about risk.

Conflict of interest I am 80 years of age. I try to avoid driving after dark.

\section{A K Adams}

12 Redwood Lodge, Grange Road, Cambridge CB3 9AR, UK

E-mail: aileen.adams@btopenworld.com

\section{REFERENCE}

1 Bache J. Reducing the toll of road traffic accidents. J R Soc Med 2003;96: 617

\section{A surgeon replies}

It is a pity that one phrase, perhaps a rather inept pleasantry in what was on the whole a friendly and sympathetic review, should have provoked sadness. Of course it's true that the College of Physicians never discovered anythingin contrast to the College of Surgeons which through the Institute of Basic Medical Sciences discovered quite a lot, and accumulated some Nobel Prizewinners.

\section{Adrian Marston}

London SW7, UK

\section{A physician objects}

In his review of my book of essays A Physician Reflects (January 2004 JRSM), Adrian Marston states that I have made a valiant attempt to credit the 'denizens of Regents Park' (i.e. the Royal College of Physicians) with the discovery of the cause of lung cancer. I made no such attempt. The College, it should be emphasized, never discovered anything. Not even the most prejudiced Fellow of the College would make such an assertion, let alone a serious student of the history of 20th century medicine. Your reviewer suggests that I will cause 'much innocent merriment among surgeons and others'. The College has paid tribute to the outstanding work of Sir Austin Bradford Hill and Sir Richard Doll on a number of occasions. Furthermore, Sir Austin was the first non-medical scientist to be elected to the Fellowship of the College, nominated by Sir Harold Himsworth, Secretary of the Medical Research Council, which gave strong support to the work of Bradford Hill and Doll. Your reviewer's remarks will cause more sadness than merriment among those serious 
historians who were kind enough to read the essays before publication.

\section{Christopher Booth}

Wellcome Centre for the History of Medicine at UCL,

24 Eversholt Street, London NW1 1AD, UK

\section{Potential of vaginal microbicides in HIV control}

The editorial by Professor Kotwal (January 2004 JRSM $M^{1}$ ) provides a very welcome commentary on South Africa's improved approach to HIV/AIDS. I am surprised, however, that he makes no mention of the potential role of vaginal microbicides in curbing the epidemic. These products are in an advanced stage of development and, like AIDS vaccines, are the subject of clinical trials taking place in several countries, including South Africa. Microbicides are gels containing selected anti-infective agents, for women to insert before sexual intercourse in order to protect themselves and their partners from HIV and other sexually transmitted infections. ${ }^{2}$ Some 20 microbicides have been successfully tested in human safety studies and several of them are scheduled to begin large-scale field trials this year to find out how well they protect women at high risk of HIV, with the results expected some 3 years later. Unlike condoms, they do not create a physical barrier to reduce sexual pleasure, and - crucially - they are controlled by the woman and will thus make a vital contribution to enhancing women's empowerment.

Microbicides are not intended to replace other vital prevention measures such as those based on health education messages, male and female condoms - or AIDS vaccines when they become available — but will give people a wider choice of potentially life-saving methods of protection.

\section{Alan Stone}

International Family Health

40 Adler Street, London E1 1EE, UK

E-mail: alan.stoneX@virgin.net

\section{REFERENCES}

1 Kotwal GJ. HIV treatment and eradication in South Africa. $J$ R Soc Med 2004;97:1-2

2 Stone AB. Microbicides: a new approach to preventing HIV and other sexually transmitted infections. Nature Rev Drug Discovery 2002;1:977-85

\section{Coal miners' chests}

The Government is currently urging coal miners or their relatives to claim compensation if the miner ever had coughing, clearing their chest or throats, breathing problems or any chest problems whatsoever. This applies whether the miner is alive or had such difficulties and is now dead. Doctors may want to bring this scheme, which ends this month (31 March 2004), to the attention of relevant patients or families. Awards can be large, and might be used, for example, to fit a stair lift or employ a carer. The contact body is the Miners \& General Workers Compensation Recovery Unit (telephone 0800085 0880).

\section{Philip Steadman}

55 Shrewsbury Lane, London SE18 3JE, UK

\section{CORRECTION}

Smoking rates in the staff of a military field hospital before and after wartime deployment

In this paper (January $2004 J R S M^{1}$ ) the pre-deployment smoking prevalence in regular Army personnel is stated in the Summary and Discussion to have been $42 \%$. This was in fact the post-deployment figure; before deployment it was $34 \%$.

\section{REFERENCE}

1 Boos CJ, Croft AM. Smoking rates in the staff of a military field hospital before and after wartime deployment. J R Soc Med 2004;97:20-2 